\title{
Mechanisms of pain relief by vibration and
}

\section{movement}

\author{
Ryusuke Kakigi, Horoshi Shibasaki
}

\begin{abstract}
Mechanisms of pain relief induced by vibration and movement were investigated. A $\mathrm{CO}_{2}$ laser beam, which is useful for pure nociceptive stimulation, was used for recording pain-related somatosensory evoked potentials (pain SEPs) and for measuring pain threshold and reaction time (RT). Concurrently applied vibratory stimuli to and active movements of the fingers significantly reduced and prolonged pain SEPs, increased pain threshold, and prolonged RT, indicating that an increase in the inhibitory mechanisms of painful feeling was induced by the concurrently adopted sensory inputs mediated by large myelinated fibres. In contrast, continuous cooling enhanced pain SEPs and decreased pain threshold, probably due to the spatial summation of two kinds of nociceptive impulses mediated by the same pathways. The results of this investigation throw light on the mechanisms of the alleviation of pain by vibration and movement.
\end{abstract}

One of the main hypotheses for the gate control theory reported by Melzack and Wall ${ }^{12}$ is that afferent signals which are mediated by large myelinated fibres inhibit small pain fibres presynaptically in the dorsal horn of the spinal cord. This hypothesis is supported by the analgesic effect of transcutaneous electrical nerve stimulation (TENS) of the peripheral nerve. ${ }^{3-6}$ There has been no method of evaluating its effect objectively, and quantitatively, however, owing to the lack of a method of applying pure thermal or painful stimuli while recording the responses from the CNS in humans. ${ }^{7}$ Golding $e t a l^{5}$ and Nardone and Schieppati ${ }^{6}$ reported the effects of TENS on waveforms of electrically-stimulated somatosensory evoked potentials (SEPs) for elucidating analgesic effects by TENS, but electric stimuli are not appropriate for the objective described above.

We studied SEPs induced by painful but tolerable $\mathrm{CO}_{2}$ laser beam (pain SEPs), ${ }^{8-13}$ and proved that ascending sensory signals induced by the beam are mediated by $\mathrm{A}$ delta fibres and the spinothalamic or spinoreticular tracts. Pain SEP findings significantly correlate with an impairment of pain-temperature sensation. We analysed the effects of various interference stimuli such as vibration, movement, touch, and cooling on the pain SEPs, pain threshold, and reaction time (RT) to the painful stimuli induced by $\mathrm{CO}_{2}$ laser stimulation. We aimed to confirm, by using objective methods, the analgesic effect by afferent signals mediated by large fibres and to elucidate its underlying mechanisms.

\section{Subjects and methods}

Fifteen normal volunteers, 11 women and four men, were studied. Their ages ranged from 21 to 36 years with the mean age of 25 . Their height ranged from 150 to $174 \mathrm{~cm}$ (mean 158). No medication was given for sedation, and subjects were kept awake. Each subject gave informed consent. A special $\mathrm{CO}_{2}$ laser stimulator for recording SEPs was made by Nippon Infrared Industries (Kawasaki, Japan). Its maximum power was $12.5 \mathrm{~W}$, and the stimulus intensity could be continuously changed. The laser wavelength was $10.6 \mu \mathrm{m}$, the diameter of the irradiation beam was about $2 \mathrm{~mm}$, and the stimulus duration was $20 \mathrm{msec}$. We adopted an intensity of approximately $18 \mathrm{~mJ} / \mathrm{mm}^{2}$ which elicited sharp pain that all subjects described as tolerable, "like a pin-prick". To avoid habituation irradiated points were moved slightly for each stimulus. The laser beam was applied to the part of the dorsum of hand innervated by the radial nerve once every 3 seconds. Subjects' eyes were protected by swimming goggles.

Silver disc electrodes $(1 \mathrm{~cm}$ diameter) were attached to the scalp with collodion and filled with electrode jelly based on the international 10-20 system. An impedance was maintained at less than $3 \mathrm{~K} \Omega$. Three exploring electrodes were placed at $\mathrm{Cz}, \mathrm{C}_{3}{ }^{\prime}$, and $\mathrm{C}_{4}{ }^{\prime}(2 \mathrm{~cm}$ behind $\mathrm{C}_{3}$ and $\mathrm{C}_{4}$, respectively). The latter two sites corresponded to the hand sensory area of each hemisphere. Linked ear lobes $(\mathrm{A} 1+\mathrm{A} 2)$ were used as the reference. The amplifier frequency response was $0 \cdot 5-30 \mathrm{~Hz}(-3 \mathrm{~dB})$. The analysis time was 1 second, and the sampling rate was $1.97 \mathrm{~ms}$. Peak latency and amplitude were measured for each recognisable component by a computer cursor. Amplitude was measured from the preceding peak of the opposite polarity. Relative positivity at grid 1 resulted in a downward deflection. Interfering stimuli were continuously applied to the fingers of the same hand throughout each recording session of pain SEPs as follows. (1) Tactile stimulation: the dorsum of the 2nd and 3rd fingers was continuously stroked by the experimenter with a soft wad of tissue paper. (2) Vibration: vibratory stimulus with a frequency of approximately $500 \mathrm{~Hz}$ was applied to the dorsum of the 2 nd and 3 rd fingers with a battery powered 
device. (3) Cooling: the 2nd and 3rd fingers were put in the chilled water with ice, the temperature of which was about $0^{\circ} \mathrm{C}$. (4) Movement: the subject was encouraged to continue a rapid drumming motion of all fingers at a self-paced rate, but to avoid contact between fingers or any other objects.

Five responses were averaged in one recording, and eight recordings were made for "control" (without interference) as well as for each "interference" SEP in a balanced design. The averaged wave forms of all responses $(5 \times 8=40)$ were computed for each stimulus condition for each subject. Detailed methods of the "interference" study are described in our previous reports. ${ }^{14-16}$

Pain threshold was measured by using the same $\mathrm{CO}_{2}$ laser stimulator in the "control" and each "interference" conditions. While a stimulus of increasing power (about every $1 \mathrm{~mJ} /$ $\mathrm{mm}^{2}$ ) was applied to the skin, subjects were requested to tell the examiner when they began feeling distinct sharp pain "like a pinprick". The test was repeated at least three times and the lowest threshold was adopted. Reaction time (RT) to the $\mathrm{CO}_{2}$ laser beam was measured in the "control" and each "interference" condition. Stimulus intensity was the same as that employed for recording pain SEPs. An interstimulus interval was at random and 3 seconds or longer. The subject was required to push a button as soon as the painful sensation was felt. More than 10 RTs were measured for each condition and the mean calculated. For comparison, RT to the electrical stimulus delivered to the median nerve at the wrist was also measured by the same paradigm as used for $\mathrm{CO}_{2}$ laser stimulation. The electrical stimulus was a constant voltage square-wave pulse lasting $0.2 \mathrm{~ms}$, and its stimulus intensity was sufficient to produce a definite twitch of the thumb. Statistical analysis of pain SEP findings, pain threshold, and RT was done by paired $t$ test between the "control" and each "interference" condition, and $p<0.02$ was accepted as significant.

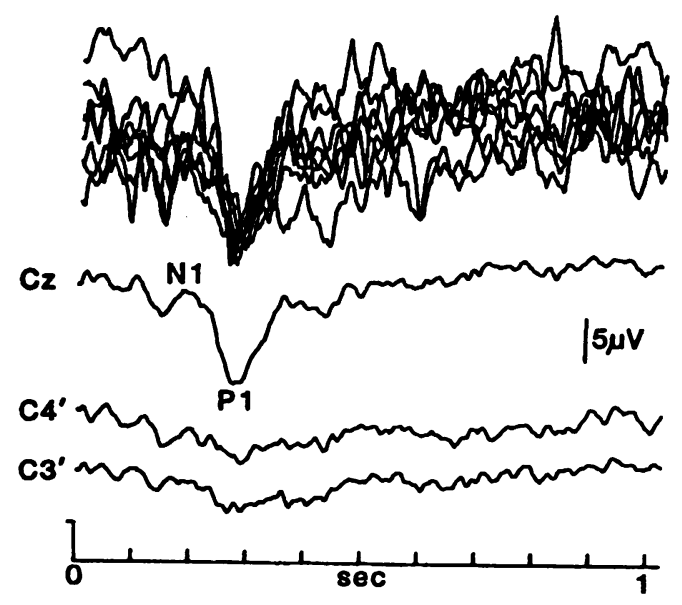

Figure 1 Averaged wave forms of pain SEPs recorded at $\mathrm{Cz}, \mathrm{C}_{3}{ }^{\prime}$, and $\mathrm{C}_{4}{ }^{\prime}$ electrode after $\mathrm{CO}_{2}$ laser stimulation to left hand with no interference (control wave form) in normal subject. Linked ear lobes were used as reference. Traces on top are superimposition of eight recordings at $\mathrm{Cz}$ electrode.

\section{Results}

PAIN SEP FINDINGS

A small negative and a large positive potential, termed $\mathrm{N} 1$ and $\mathrm{Pl}$, respectively, were identified in the "control" and each "interference" trial in all 15 subjects. As the responses recorded at the $\mathrm{Cz}$ electrode were much larger than those at $\mathrm{C}_{3}{ }^{\prime}$ or $\mathrm{C}_{4}{ }^{\prime}$ (figure 1) the former were analysed. The mean peak latencies of $\mathrm{N} 1$ and P1 in the "control" were 205.6 and $302.5 \mathrm{~ms}$, respectively, and their amplitudes were $2.23 \mu \mathrm{V}$ and 8.07 $\mu \mathrm{V}$, respectively (table 1). Amplitude of both $\mathrm{N} 1$ and P1 recorded at $\mathrm{C}_{4}$ ' was not significantly different from that at $\mathrm{C}_{3}$ '.

Peak latencies of $\mathrm{N} 1$ and $\mathrm{Pl}$ were significantly prolonged in "movement" and "vibration" interference (table 1 and figure 2). Amplitude of both $\mathrm{N} 1$ and P1 was decreased by "movement" and "vibration" interference, and a change of P1 in both conditions was significantly large ( $p<0.01$; table 1 and figure 2). Amplitude change by "tactile" interference was not consistent. In contrast, amplitude of both $\mathrm{N} 1$ and P1 was increased by the "cooling" interference, particularly $P 1 \quad(p<0.01$; table 1 and figure 2). Wave form changes were also identified in each interference condition recorded at the $\mathrm{C}_{3}{ }^{\prime}$ and $\mathrm{C}_{4}$ ' electrode, but their degrees were much smaller than those at the $\mathrm{Cz}$. For example, the percentage of the amplitude decreased by the "movement" interference was $18.9 \%, 40.3 \%$, and $20.0 \%$ at the $\mathrm{C}_{3}{ }^{\prime}, \mathrm{Cz}$, and $\mathrm{C}_{4}{ }^{\prime}$ electrode, respectively.

\section{PAIN THRESHOLD}

The mean (SD) of pain threshold in "control" was $13.6(0.5) \mathrm{mJ} / \mathrm{mm}^{2}$. Pain thresholds in "movement" and "vibration" interference conditions were the same with or higher than that of "control" in all subjects, and their changes were significant, particularly for "vibration" interference (table 2). In contrast, pain threshold in the "cooling" interference condition was the same as or smaller than that of "control" in all subjects, and the difference between them was significant (table 2).

REACTION TIME (RT)

The mean (SD) RT to the $\mathrm{CO}_{2}$ laser stimulus in the "control" condition was $334 \cdot 7$ $(27 \cdot 2) \mathrm{ms}$. It was increased in all "interference" conditions except "cooling", and the change in "movement" and "vibration" interference was significant (table 3 ). The mean (SD) RT to electrical stimulation applied to the median nerve at the wrist was 170.0 $(30.2) \mathrm{ms}$. The difference between the peak latency of $\mathrm{N} 1$ and $\mathrm{RT}$ (N1-RT) was also measured; that in "movement" and "vibration" interference conditions was significantly longer than that in the "control" condition (table 3). N1-RT in the "tactile" and "cooling" interference conditions was shorter than that in the "control" condition, but the changes were not significant. As the peak latency of P1 was longer than RT in several subjects, P1-RT was not measured. 
Table 1 Latencies and amplitudes of pain SEPs recorded at $\mathrm{Cz}$ without (control) and with various interference

\begin{tabular}{|c|c|c|c|c|c|}
\hline & Control & Tactile & Movement & Vibration & Cooling \\
\hline \multicolumn{6}{|l|}{$\begin{array}{l}\text { Mean (SD) peak latency } \\
\text { (msec) }\end{array}$} \\
\hline $\begin{array}{l}\text { N1 } \\
\text { P1 } \\
\text { Mean }(\mathrm{SD}) \text { amplitude }(\mu \mathrm{V})\end{array}$ & $\begin{array}{l}205 \cdot 6(24 \cdot 6) \\
302.5(18 \cdot 6)\end{array}$ & $\begin{array}{l}216 \cdot 8(31 \cdot 3) \\
310 \cdot 3(19 \cdot 0)\end{array}$ & $\begin{array}{l}224 \cdot 4^{\star \star}(30 \cdot 8) \\
317 \cdot 7^{\star}(34 \cdot 4)\end{array}$ & $\begin{array}{l}232 \cdot 1^{\star \star}(25.7) \\
336 \cdot 5^{\star \star}(28 \cdot 9)\end{array}$ & $\begin{array}{l}212 \cdot 3(23.1) \\
312 \cdot 5(18 \cdot 8)\end{array}$ \\
\hline $\begin{array}{l}\text { N1 } \\
\text { P1 }\end{array}$ & $\begin{array}{l}2.23(0.92) \\
8.07(2.74)\end{array}$ & $\begin{array}{l}2.09(1.03) \\
9 \cdot 18(4 \cdot 01)\end{array}$ & $\begin{array}{l}1 \cdot 87(1 \cdot 11) \\
4 \cdot 82^{\star \star}(2 \cdot 33)\end{array}$ & $\begin{array}{l}1 \cdot 89(1 \cdot 54) \\
6 \cdot 28^{\star \star}(2 \cdot 80)\end{array}$ & $\begin{array}{l}2 \cdot 47(1 \cdot 48) \\
10 \cdot 50^{\star \star}(4 \cdot 53)\end{array}$ \\
\hline
\end{tabular}

\section{Discussion}

$\mathrm{A} \mathrm{CO}$ laser beam applied in an appropriate condition seems a good method for analysing pain mechanisms because it provides a pure

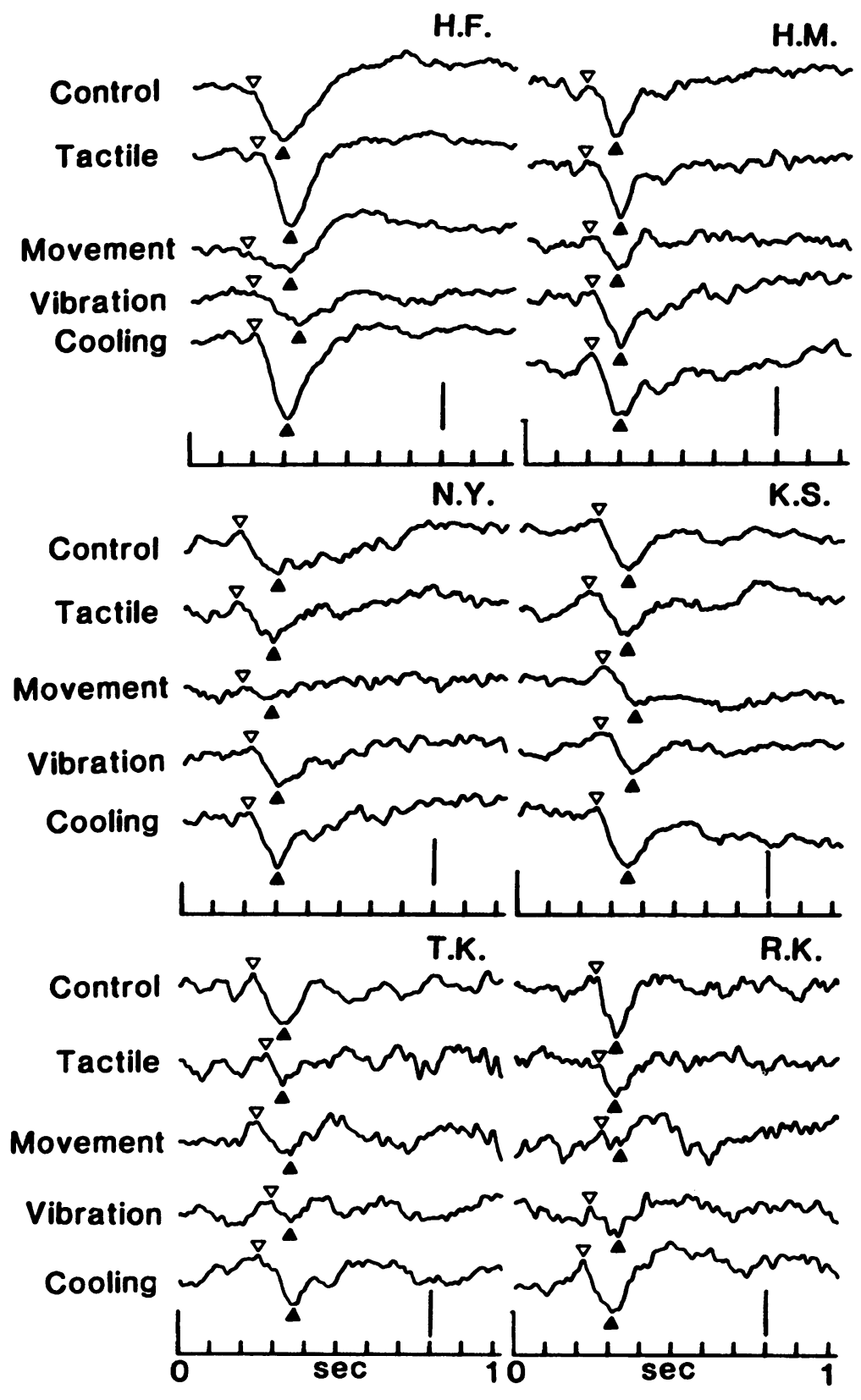

Figure 2 Averaged wave forms of pain SEPs in various conditions in six normal subjects. $\mathrm{CO}_{2}$ laser beam was radiated to part of dorsum of left hand innervated by radial nerve. $C z-A 1 A 2$ derivation. Control = pain SEPs with no interference. Tactile, Vibration, and Cooling = pain SEPs with tactile, vibration, and cooling interference, respectively, applied to 2nd and 3rd fingers continuously and concurrently with $\mathrm{CO}_{2}$ laser stimulation. Movement = pain SEPs with continuous active movements of 2 nd and 3 rd fingers of left hand. Open and closed triangles indicate N1 and P1 peak, respectively. Both peaks tend to be prolonged and poorly formed with Movement and Vibration interference but are sharper with Cooling interference. Effect of Tactile interference is not consistent. Scale bar shows $10 \mu \mathrm{V}$ in subjects 1 to 4 and $5 \mu \mathrm{V}$ in subjects 5 and 6. thermal and painful stimulation without causing mechanical distortion of the skin and it is possible to trigger other instruments with no time lag. A few laboratories have also studied pain SEPs by using $\mathrm{CO}_{2}$ laser in normal subjects and reported similar wave forms to those of ours. ${ }^{17-19}$

As both $\mathrm{N} 1$ and $\mathrm{P} 1$ are maximal around the vertex and symmetrically distributed, as reported in our previous reports, ${ }^{89}$ and as in this study, the interference effects at $\mathrm{Cz}$ are much larger than those at $\mathrm{C}_{3}{ }^{\prime}$ or $\mathrm{C}_{4}{ }^{\prime}$, the generator source of $\mathrm{N} 1$ and $\mathrm{P} 1$ may be in the thalamus or both parietal lobes rather than the primary sensory cortex. The second sensory cortex (S II) and the cingulate gyrus should also be considered as the main sites for pain perception. The former was proposed by Hari and her colleagues by results of magnetoencephalogram after painful dental ${ }^{20}$ and nasal mucosa stimulation. ${ }^{21}$ The latter was proposed by Talbot $e t a^{22}$ by analysing positron emission tomography during noxious thermal stimulation.

We reconfirmed the presence of pain relief by vibration and movement, which is consistent with the gate control theory reported by Melzack and Wall. ${ }^{12}$ Unfortunately, it is impossible to record clear pain SEPs from the peripheral nerve or the spinal cord probably due to the small $\mathrm{S} / \mathrm{N}$ ratio. ${ }^{8}$ Therefore, the site where the interference effects are mainly caused and its underlying mechanisms have to be estimated from other information. It is, of course, possible that the interference occurred in the dorsal horn of the spinal cord as proposed by Melzack and Wall. ${ }^{12}$ In that case, the innocuous vibratory stimuli or movements reduce the excitability of laser-activated dorsal horn neurons, thus reducing the number of activated spinothalamic tract neurons and simultaneously reducing the synchronicity of the active volley reaching the cerebral hemisphere. This would both reduce the amplitude and increase the latency of $\mathrm{N} 1$ and $\mathrm{P} 1$ and elevate the pain threshold.

It is also possible that the interference occurred in the cerebral hemisphere. If RT was represented by a loop in which the evoked potential latency represented the afferent limb and the difference between the evoked potential latency and RT represented the efferent limb the significant increase in the time interval (N1-RT) by movement and vibration interference suggest that the interference effects were caused in the cerebral hemisphere. The more pronounced degradation of the second potential (P1) compared with that of 
Table 2 Pain threshold $\left(\mathrm{mf} / \mathrm{mm}^{2}\right)$ in "control" and each "interference" condition

\begin{tabular}{llllll}
\hline & Control & Tactile & Movement & Vibration & Cooling \\
\hline Mean (SD & $13.6(0.5)$ & $13.9(0.6)$ & $14 \cdot 5^{\star \star}(0.5)$ & $14 \cdot 9^{\star \star}(0.5)$ & $13 \cdot 1^{\star \star}(0.4)$ \\
\hline
\end{tabular}

Significance of difference between control and each interference trial calculated by paired $t$ test $\left({ }^{\star} \mathrm{p}<0.02,{ }^{\star \star} \mathrm{p}<0.01\right)$.

Table 3 Reaction time (RT) (ms) to $\mathrm{CO}_{2}$ laser stimulation and the time interval between N1 of pain SEP and RT in "control" and each "interference" condition

\begin{tabular}{llllll}
\hline & Control & Tactile & Movement & Vibration & Cooling \\
\hline Mean (SD) Reaction timet & $334 \cdot 7(27 \cdot 2)$ & $341 \cdot 6(29 \cdot 8)$ & $372 \cdot 0^{\star \star}(37 \cdot 7)$ & $398 \cdot 7^{\star \star}(57 \cdot 3)$ & $323 \cdot 0(33 \cdot 4)$ \\
Mean (SD) N1-reaction time $129 \cdot 1(30 \cdot 2)$ & $124 \cdot 8(41 \cdot 2)$ & $147 \cdot 6^{\star}(38 \cdot 5)$ & $166 \cdot 7^{\star \star(58 \cdot 7)}$ & $111 \cdot 7(25 \cdot 7)$ \\
\hline
\end{tabular}

Significance of difference between control and each interference trial calculated by paired $t$ test $\left({ }^{\star} \mathrm{p}<0.02,{ }^{\star \star} \mathrm{p}<0.01\right.$ ).

†Mean (SD) of reaction time to electrical stimulation of median nerve at wrist was $170 \cdot 0(30 \cdot 2) \mathrm{ms}$.

$\neq$ Difference between peak latency of $\mathrm{N} 1$ and reaction time.

the primary potential (N1) also seems to indicate the cerebral hemisphere as the responsible site for the interference effects. Several hypotheses may account for this particular phenomenon. If some neurons in the thalamus or the cerebral cortex receive inputs not only from nociceptors through small fibres but also from mechanoreceptors through large fibres, interactions are expected to take place. Mechanisms underlying the inhibition of electric SEPs by "movement", "vibration", or "tactile" interference, so-called "gating", 14-16 23-30 are generally explained by this hypothesis. In addition, we propose two hypotheses in relation to the cognitive process as a higher function of the CNS. The first is that humans cannot completely differentiate painful stimulation from sensory stimulation of other modalities which are applied concurrently, and tend to neglect unpleasant sensations. The second is that painful sensation is attenuated by an attention to ascending signals of other modalities such as vibration.

The effects of "tactile" interference were fairly small compared with those of active movement or vibration interference, suggesting that the signals mediated by small fibres are not attenuated as much as those mediated by cutaneous sensory fibres as by movement or vibration. A prominent tactile interference effect on electric SEPs ${ }^{14-16}$ has to be explained by a different mechanism underlying the interference between them. It is difficult to elucidate the underlying mechanisms of the contrary effect by the cooling interference. Continuous stimulation of the nociceptors by cooling during the superimposed laser stimulation might increase the excitability of the appropriate dorsal horn neurons and then that particular phenomenon might have the effects of increasing the synchronicity of the volley and the number of spinothalamic tract fibres producing an increased amplitude of N1 and $\mathrm{P} 1$ and a reduction of the pain threshold. The fact that painful sensation caused by injury in cold weather is felt more than that in warm weather might be compatible with this particular finding.

This investigation was supported by The Brain Science Foundation, The Kato Memorial Trust for Nambyou Research, The Ministry of Health and Welfare (Research Committee of The
Long Life Science), and The Ministry of Education, Science and Culture (Research Committee of The Integrative Studies on Physiological Functions and Grant-In-Aid for Encouraging Young Doctors) for RK and The National Center for Nervous, Mental and Muscular Disorders (Research Committee of Myelopathy) for RK and HS.

1 Melzack R, Wall PD. Pain mechanisms: a new theory. Science 1973;150:971-9.

2 Wall PD. The gate control theory of pain mechanisms. A reexamination and re-statement. Brain 1978;101:1-18.

3 Swett JE, Law JD. Analgesia with peripheral nerve stimulation: absence of a peripheral mechanisms. Pain 1983;15:55-70.

4 Eriksson MBE, Rosén I, Sjölund B. Thermal sensitivity in healthy subjects is decreased by a central mechanism after TNealthy subjects is decreased

5 Golding JF, Ashton H, Marsh R, Thompson JW. Transcutaneous electrical nerve stimulation produces variable neous electrical nerve stimulation produces variable
changes in somatosensory evoked potentials, sensory changes in somatosensory evoked potentials, sensory
perception and pain threshold: clinical implications for pain relief. $f$ Neurol Neurosurg Psychiatry 1986;49:1397-406.

6 Nardone A, Schieppati M. Influences of transcutaneous electrical stimulation of cutaneous and mixed nerves on subcortical and cortical somatosensory evoked potentials. Electroencephalogr Clin Neurophysiol 1989;74:24-35.

7 Kakigi R, Shibasaki H. Scalp topography of mechanically and electrically evoked somatosensory potentials in man. Electroencephalogr Clin Neurophysiol 1984;59:44-56.

8 Kakigi R, Shiasaki H. Ikeda A. Pain-related somatosensory evoked potentials following $\mathrm{CO}_{2}$ laser stimulation in man.

9 Kakigi R, Shibasaki H, Neshige R, Ikeda A, Mamiya K, Kuroda Y. Pain-related somatosensory evoked potentials in cortical reflex myoclonus. $\mathcal{F}$ Neurol Neurosurg Psychiatry in cortical reflex

10 Kakigi R, Shibasaki H. Estimation of conduction velocity of the spino-thalamic tract in man. Electroencephalogr Clin Neurophysiol 1991;80:39-45.

11 Kakigi R, Shibasaki H, Tanaka $\mathrm{K}$, et al. $\mathrm{CO}_{2}$ laser-induced pain-related somatosensory evoked potentials in peripheral neuropathies: correlation between electrophysiological and histopathological findings. Muscle Nerve 1991;14:441-50.

12 Kakigi R, Shibasaki H, Kuroda Y, et al. Pain-related somatosensory evoked potentials in syringomyelia. Brain (in press).

13 Kakigi R, Endo C, Neshige R, Kuroda Y, Shibasaki H. Estimation of conduction velocity of $A$ delta fibers in Estimation of conduction velocity

14 Kakigi R, Jones SJ. Effects of median nerve SEPs of tactile stimulation applied to adjacent and remote areas of the stimulation applied to adjacent and remote areas of the
body surface. Electroencephalogr Clin Neurophysiol body surface.

15 Kakigi $R$. Ipsilateral and contralateral SEP components following median nerve stimulation: Effects of interfering stimuli applied to the contralateral hand. Electroencephalogr Clin Neurophysiol 1986;64:246-59.

16 Kakigi R, Jones SJ. Influence of concurrent tactile stimulation on somatosensory evoked potentials following posterior tibial nerve stimulation in man. Electroencephalogr Clin Neurophysiol 1986;65:118-29.

17 Carmon A, Friedman Y, Coger R, Kenton B. Single analysis of evoked potentials to noxious thermal stimulation in man. Pain 1980;8:21-32.

18 Treede R-D, Kief S, Hölzer T, Bromm B. Late somatosensory evoked cerebral potentials in response to cutaneous heat stimuli. Electroencephalogr Clin Neurophysiol 1988; 70:429-41.

19 Arendt-Nielsen L. First pain event related potentials to argon laser stimuli: recording and quantification. $\mathcal{f}$ Neurol Neurosurg Psychiatry 1990;53:398-404. 
20 Hari R, Kaukoranta E, Reinikainen K, Huopaniemie T, Mauno J. Neuromagnetic localization of cortical activity evoked by painful dental stimulation in man. Neurosci Lett 1983;42:77-82.

21 Huttunen J, Kobal G, Kaukoranta E, Hari R. Cortical responses to painful $\mathrm{CO}_{2}$ stimulation of nasal mucosa; a magnetoencephalographic study in man. Electroencephalogr Clin Neurophysiol 1986;64:347-9.

22 Talbot JD, Marrett S, Evans AC, Meyer E, Bushnell MC, Duncan GH. Multiple representations of pain in human cerebral cortex. Science 1991;251:1355-8.

23 Rushton DN, Rothwell JC, Craggs MD. Gating of somatosensory evoked potentials during different kinds of movement in man. Brain 1981;104:465-91.

24 Cohen LG, Starr A. Localization, timing and specificity of gating of somatosensory evoked potentials during active movement in man. Brain 1987;110:451-67.

25 Cheron G, Borenstein S. Specific gating of the early somatosensory evoked potentials during active movement. Electroencephalogr Clin Neurophysiol 1987; 67:537-48.
26 Jones SJ, Halonen J-P, Shawkat F. Centrifugal and centripetal mechanisms involved in the "gating" of cortical SEPs during movement. Electroencephalogr Clin Neu27 rophysiol 1989;74:36-45.

Abbruzzese G, Abbruzzese M, Favale E, Ivaldi M, Leandri $M$, Ratto $S$. The effect of hand muscle vibration on the somatosensory evoked potential in man: an interactio between lemniscal and spino-cerebellar inputs? $\mathcal{F}$ Neurol Neurosurg Psychiatry 1980;43:433-7.

28 Jones SJ. An "interference" approach to the study of somatosensory evoked potentials in man. Electroencephalogr Clin Neurophysiol 1981;52:517-30.

29 Ibañez V, Deiber MP, Mauguière F. Interference of vibrations with input transmission in dorsal horn and cuneate nucleus in man: a study of somatosensory evoked potentials (SEPs) to electrical stimulation of median nerve and fingers. Exp Brain Res 1989;75:599-610.

30 Reisin RC, Goodin DS, Aminoff MJ, Mantle MM Effects of different sensory inputs on the median-derived Effects of different sensory inputs on the median-derived
somatosensory evoked potential. Muscle Nerve 1989;12:598-603. 